International Journal of Engineering, Science and Technology

Vol. 7, No. 2, 2015, pp. 11-26
INTERNATIONAL

JOURNAL OF

ENGINEERING,

SCIENCE AND

TECHNOLOGY

www.ijest-ng.com

www.ajol.info/index.php/ijest

(C) 2015 MultiCraft Limited. All rights reserved

\title{
Optimization of hybrid system (wind-solar energy) for pumping water
}

\author{
S. Laamari ${ }^{1}$, W. Zghal ${ }^{1} *$, H. Kchaou ${ }^{1}$ \\ ${ }^{1}$ Laboratory of Electromechanical Systems, National Engineering School of Sfax, B.P. W3038, Sfax, TUNISIA \\ *Corresponding Author: e-mail address: zghal_wissem@yahoo.fr, Tel +21697750882
}

\begin{abstract}
This paper presents an optimization method for a hybrid (wind-solar) autonomous system designed for pumping water. This method is based on mathematical models demonstrated for the analysis and control of the performance of the various components of the hybrid system. These models provide an estimate of recoverable solar energy depending on the climatic conditions of a given area and a determination of the energy produced by a solar panel. These models also show evaluation of the electrical energy produced by the wind generator. Moreover, this optimization method is based on minimizing of the factor lack of energy to generate (LEG) by variation of the duration of pumping and the angel of inclination of panels. To validate this method, a case study was performed on an installed system in the region of "Sidi Makhlouf" in southern Tunisia. The results confirm that it is technically advantageous to use renewable energy for pumping water.
\end{abstract}

Keywords: Renewable energy; pumping water; technical optimization; autonomous system.

DOI: http://dx.doi.org/10.4314/ijest.v7i2.2

\section{Introduction}

Since the 19th century, the world has suffered from several complex problems that seriously affect the environment such as the significant increase in the planet temperature and the increased concentrations of greenhouse gas emissions. These problems have led to a climate change and especially the decrease in precipitation, which affects significantly the potential of water. Like all Southern countries, Tunisia is also suffering from water scarcity due to the global warming and climate change. To meet water needs, several strategies have been followed in Tunisia. One of the solutions is pumping water using available renewable energy. The potentialities regarding renewable resources of energy are important in Tunisia. The solar energy is an ideal exhibition, Tunisia benefits from a privileged geographical position which assures a very good sunshine value during the complete year. These values are considered between a minimum of $1550 \mathrm{kWh} / \mathrm{m}^{2} /$ year in the northwest of the country and a maximum of $1900 \mathrm{kWh} /$ $\mathrm{m}^{2} /$ year in the center and the Gulf of Gabes.

The country already start on a mega-project of solar power production (2000 MW) intended for the export towards Europe which consists in producing electricity by using the CSP technology (Concentration of the solar energy) installed in the Tunisian desert. The first wind power station of electricity production was created in 2000 in Sidi Daoud, in the northeast of the country. It is a power station with the capacity of 20MW. The Tunisian Company of Electricity and Gas (STEG) intends to accomplish an extension project of this wind station to increase its capacity to $53.6 \mathrm{MW}$, which corresponds to $1.5 \%$ of the total power production. The national objective is to reach 100MW by 2009 (Zghal et al, 2011).

In the literature, we notice that there is a big difference between the methods of modeling, especially for the photovoltaic systems which is related to the estimation of the sun radiation. There are several authors which are interested in the modeling of the sun radiation. Among these works, we can quote R.F Mechlouch and al. (2003) who developed a model related to the cloudiness of a site for the estimation of the density of the global solar flow in the city of Gabes. There is also the empirical method of Perrin Brichambaut (1980) to model an incidental radiation to decompose it into several radiations which vary according to the height of the sun, the angle of incidence, weather and the state of visibility of the atmosphere. 
Amar et al. (2008) have statistically analyzed the wind energy potential of the Sidi Daoud site (Tunisia): Weibull and Rayleigh parameters at a height of $30 \mathrm{~m}$ have been estimated and used to describe the distribution and behavior of annual wind speeds and their frequencies at site. Zghal et al. (2011) presents an investigation of the wind power potential using real wind data for five sites in Tunisia: Jendouba, Bizerte, Sfax, Gafsa and Jarzis. The Weibull distribution functions and the Betz theory are applied to describe the wind speed distribution and to determinate the wind power density for these sites. Also, mathematical models are used to calculate the recoverable wind power and the wind energy produced by a wind turbine

In this context, this study was conducted in association with the Regional Commission for Agricultural Development in Medenine (CRDA), whose objective to guarantee needed energy for an autonomous hybrid system for pumping water by choosing the optimal characteristics of the different components of the installation (wind generator, photovoltaic panels). Therefore, a study of the exploitation of solar and wind energy for decentralized power generation is performed. The advantages and disadvantages of using each source were analyzed to determine the best configuration of the system. In addition, a study of the pumping system and the characteristics of the drilling have been completed: in this study, we tried to determine the optimum pumping duration that we can fix to the existing installation.

\section{Theoretical study}

\subsection{Hybrid system presentation}

The hybrid generator is constituted of a wind generator and photovoltaic field. To be able to transform the hybrid energy into electricity and exploit the Moto-pump, it is necessary to arrange an energizing system that ensures the conversion of energy. The command system ensures the control of the different components. The system is shown in Figure 1.

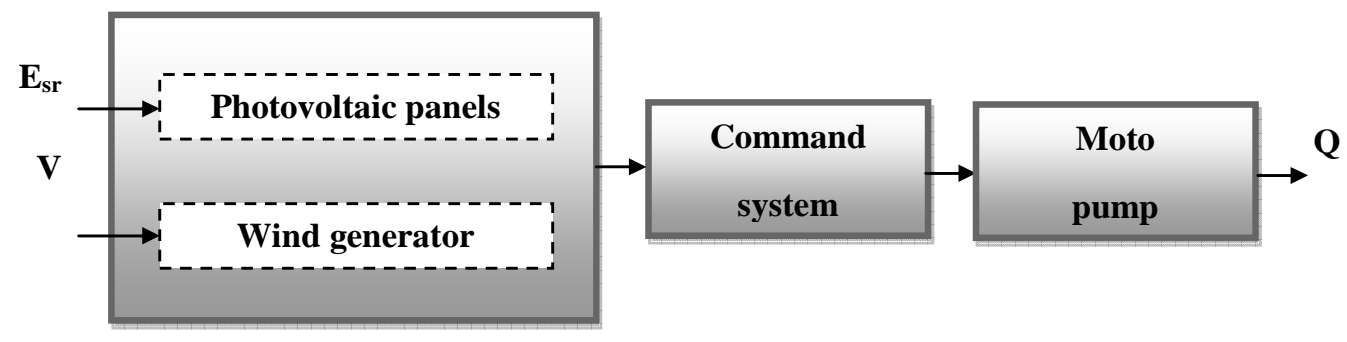

Figure 1. Schematic presentation of an autonomous hybrid system

\subsection{Modeling of the photovoltaic panels}

\subsubsection{Modeling of the Solar Radiance}

The most important characteristic of a photovoltaic panel lies is power that it can supply which is essentially related to the solar radiation given in the area. So, the modeling of the photovoltaic field starts by the modeling of the solar radiation, which depends on azimuthal coordinates of the sun and on the equatorial coordinates of the earth. The position of the sun is spotted all the time of the day and of the year by two different systems of coordinates: equatorial and horizontal coordinates. To locate the position of the sun in the equatorial system, we use two coordinates: the declination angle " $\delta$ " and the hour angle " $\omega$ ".

The declination " $\delta$ " is the angle, which makes the direction of the sun with its projection on the equatorial plan, which is approximately given by the following formula (Yang 2007; Kolhe 2003):

$$
\delta=23,45 \cdot \sin \left(\frac{360}{365} \times(j+284)\right)
$$

where $\mathrm{j}$ is the calendar day of a year (until 1 to 365 )

The hour " $\omega$ " is the angle included between the meridian passing by the South and the projection of the sun on the equatorial plan; it measures the course of sun in the sky. The hourly angle can be calculated as follows (Yaiche 2007):

$$
\omega=15 .(T S V-12)
$$

where TSV is the true solar time, which is equal to time legal corrected by a due gap aside between the longitude of the place and the longitude references (Perrin 1963). 


$$
T S V=T L-D E+\left(\frac{C C+4 \lambda}{60}\right)
$$

where:

- TL: legal time given by a watch

- DE: time difference with regard to the meridian of Greenwich, equal to 1 for Tunisia.

- $\lambda$ : Longitude of place.

The correction of the equation of time "CC" is given by the following equation (Perrin 1963):

$$
C C=9,87 \cdot \sin \left(2 \cdot\left(\frac{360}{365} \cdot(j-81)\right)\right)-7,53 \cdot \cos \left(\frac{360}{365}(j-81)\right)-1,5 \cdot \sin \left(\frac{360}{365} \cdot(j-81)\right)
$$

To locate the position of the sun in the sky, a local coordinates system, entitled system of azimuthally coordinates or horizontal coordinates is used. The horizontal mark is formed by the plan of the astronomical horizon and the vertical line of the place. In this mark, the coordinates represent the height of the sun noted " $h$ " and the azimuth " $\psi$ ".

The height of the sun " $h$ " is given by (Yaiche 2007; Fauladgar 1980):

$$
\sinh =\sin \varphi \cdot \sin \delta+\cos \varphi \cdot \cos \delta \cdot \cos \omega
$$

where: $\varphi$ is the latitude of the region.

The azimuth of the sun " $\psi$ " is the included angle between the projection of the direction of the sun on the horizontal plan and the south direction (Perrin 1963).

$$
\psi=\arcsin \left(\cos \delta \cdot \sin \omega \cdot \cos ^{-1} h\right)
$$

The modeling of the solar irradiations is very complicated due to the climatic variations. The empirical method of Perrin Brichambaut (Perrin 1963) predicts the energy received by photovoltaic cells.

In order to reduce the error, we have to determine the global radiation received by a horizontal plan " $\mathrm{G}_{\mathrm{h}}$ ", calculated as follows (Perrin 1963):

$$
G_{h}=D_{h}+I_{d} \cdot \sinh
$$

For a clear sky, the direct solar radiation $\left(I_{d}\right)$ is given by the following relations (Perrin 1963; Ben Slama 2010):

$$
I_{d}=1230 \cdot \exp \left(\frac{-1}{3,8 \cdot \sin (h+1,6)}\right)
$$

The diffuse radiation " $\mathrm{D}_{\mathrm{h}}$ " on a surface is given by (Perrin 1963):

$$
D_{h}=125 .(\sinh )^{0,4}
$$

The radiation received by any plan is the result of two forms: the direct solar radiation " $I_{d}$ " and the diffuse solar radiation " $\mathrm{D}_{\mathrm{i}}$ ". Consequently, the global radiation received by the titled plane of the cells noted " $\mathrm{G}_{\mathrm{i}}$ " will be then (Perrin 1963):

$$
G_{i}=I_{d} \cdot \cos i+D_{i}
$$

where: (i) is the angle of incidence on a inclined plan given by the relation (Zarai 2010):

$$
\cos i=\cos \delta \cdot \cos \omega \cdot \cos (\varphi-\beta)+\sin \delta \cdot \sin (\varphi-\beta)
$$

where $\beta$ is the incline angle of the photovoltaic panels.

$D_{i}$ is the diffuse radiation received by the titled array, calculated by (Perrin 1963): 


$$
D_{i}=\left(\frac{1+\cos \beta}{2}\right) \cdot D_{h}+\left(\frac{1-\cos \beta}{2}\right) \cdot \alpha^{*} \cdot G_{h}
$$

where: $\alpha^{*}$ is the Albedo coefficient corresponds to the coefficient of reflection of the ground situated in front of the sensor.

According to the formula of Schwartz (Schawartz 1980), the actually energy received by a tilted plane can be expressed as follows:

$$
E_{r}=\frac{2}{\pi} \cdot S S_{0} \cdot G_{i}
$$

where $\mathrm{SS}_{0}$ is the maximal duration of sunshine (hour) given by (Mechlouch 2003; Sanjay Kumar 2010):

$$
S S_{0}=\frac{2}{15} \cdot \operatorname{arcos}(-\operatorname{tg} \varphi \cdot \operatorname{tg} \delta)
$$

\subsubsection{Modeling of the photovoltaic generator}

The most important characteristic for the modeling of a photovoltaic generator is the determination of the electrical energy produced by a specific surface tilted " $E_{p v}$ ". This energy depends on the total energy received by the photovoltaic panel " $E_{r}$ " and the total surface of the field " $\mathrm{S}_{\mathrm{pv}}$ " (Zghal 2012).

$$
E_{p v}=E_{r} \cdot \eta_{t} \cdot S_{p v}
$$

The total efficiency " $\eta_{\tau}$ " of a photovoltaic panel is expressed as follows (Zghal 2012):

$$
\eta_{t}=\eta_{p} \cdot\left(1+B \cdot\left(T_{c}-T_{r}\right)\right)
$$

where:

- $\eta_{\mathrm{p}}$ is the panel output determined from the efficiency of photovoltaic cell that constitutes the panel;

- $\mathrm{B}$ is the temperature coefficient. It varies between 0,004 and 0,006 ;

- $\mathrm{T}_{\mathrm{r}}$ is the reference temperature of the panel (generally equal to $25^{\circ} \mathrm{C}$ );

- $\mathrm{T}_{\mathrm{c}}$ is the cells temperature.

The Cells temperature depends on the ambient temperature and the solar radiance received by the panel. It can be determined as follows (Zghal 2012):

$$
T_{c}=T_{a}+G_{h} \cdot\left(\frac{N O C T-T_{a, N O C T}}{G_{N O C T}}\right)
$$

where:

- $\mathrm{T}_{\mathrm{a}}$ is the ambient temperature;

- NOCT: is the nominal temperature of cells;

- $\mathrm{T}_{\mathrm{a}, \mathrm{NOCT}}=20^{\circ} \mathrm{C}$;

- $\mathrm{G}_{\mathrm{NOCT}}=800 \mathrm{~W} / \mathrm{m}^{2}$.

The panel output " $\eta_{\mathrm{p}}$ " and the nominal temperature of cells are the panel characteristics delivered by the constructor.

The total area " $\mathrm{S}_{\mathrm{pv}}$ " of the photovoltaic panels is given by:

$$
S_{p v}=N_{s} \cdot N_{p} \cdot N_{c e l}
$$

where:

- $\mathrm{S}_{\mathrm{cel}}$ : surface of one cell;

- $\mathrm{N}_{\mathrm{s}}$ : number of cells in series.

- $\mathrm{N}_{\mathrm{p}}$ : number of cells in parallel.

2.3Modeling of the wind generator

The characteristics of the wind generators differ from one type to another and from a manufacturer to other of the same power. The most important parameter is the output power, which strictly depends on the speed of the wind " $\mathrm{V}$ " and the area of the wind turbine.

The wind speed varies using the height to the ground " $\mathrm{H}$ " according to the following function (Zghal 2011): 


$$
\frac{V}{V_{0}}=\left(\frac{H}{H_{0}}\right)^{n}
$$

where:

- $\mathrm{V}_{0}$ : wind speed at the height $\mathrm{H}_{0}$;

- $\mathrm{n}$ : coefficient that varies between 0,1 and 0,4 . The lowest values correspond generally to the strongest and vice versa.

The transmitted power by wind generator " $\mathrm{P}_{\mathrm{t}}$ " is generally deduced from the wind power using the power coefficient " $\mathrm{Cp}$ " (Zghal 2011):

$$
P_{t}=\frac{1}{2} \cdot C_{p} \cdot \rho \cdot S \cdot V^{3}
$$

For a wind turbine, the available energy "Ew" on day, by unit of surface, is calculated by the expression (Ben Amar 2006):

$$
E_{w}=24 \cdot P_{t}
$$

\subsection{Modeling of the motor-pump}

The necessary electric energy " $\mathrm{E}_{\mathrm{e}}$ " to raise a certain quantity of water $\mathrm{Q}$ [ $\mathrm{m}^{3} / \mathrm{day}$ ] on a certain height during a day is calculated from the formula (22). This energy is reciprocally proportional to the efficiency on the group motor-pump used (Hrayshat 2004).

where:

$$
E_{e}=\frac{C_{H} \cdot H M T \cdot Q}{R_{p}}
$$

- $\mathrm{C}_{\mathrm{H}}$ (hydraulic constant) is an hydraulic constant. $\mathrm{C}_{\mathrm{H}}=\mathrm{g} . \sigma=9.806\left(\mathrm{~m} \cdot \mathrm{s}^{-2}\right) \times 10^{3}\left(\mathrm{~kg} \cdot \mathrm{m}^{-3}\right)=9806 \mathrm{~kg} \cdot \mathrm{m}^{-2} \cdot \mathrm{s}^{-2}$

$$
=\frac{9.806\left(\mathrm{~m} \cdot \mathrm{s}^{-2}\right) \times 10^{3}\left(\mathrm{~kg} \cdot \mathrm{m}^{-3}\right)}{\frac{3600 \mathrm{~s}}{1 \mathrm{~h}}}=2,725 \mathrm{~kg} \cdot \mathrm{h} \cdot \mathrm{s}^{-3} \cdot \mathrm{m}^{-2}
$$

- Rp: efficiency of the group motor-pumps is from $30 \%$ to $45 \%$, depending on the type of pump and engine.

- HMT: total manomatric height (m)

\subsection{Optimization criteria}

Tools of the system optimization from the different equations of the various states of the studied system will be presented. In this study, a technical model for the determination and the classification of the optimal characteristics of the various elements of an autonomous hybrid system is developed. This model is based on two main factors: the lack of energy to generate "LEG" and the surplus of energy produced "SEP".

To determine the consumer's total consumption, it is necessary to calculate the daily energizing need "Bj" that can be obtained as follows:

$$
B_{j}=\frac{q \cdot D \cdot C_{H} \cdot H M T}{R_{p}}
$$

where $\mathrm{q}$ is the debit of pumping water $(1 / \mathrm{s})$ and $\mathrm{D}$ is the duration of pumping water (h/day).

In fact, it is noted that the total energy produced by the hybrid system " $E_{h}$ ", given by formula (24), can or cannot satisfy the daily demand of energy.

$$
E_{h}=E_{w}+E_{p v}
$$

So, three different situations can arise during the daytime which depends on the quantity of energy needed and the total energy produced:

- $\mathrm{E}_{\mathrm{h}}<\mathrm{B}_{\mathrm{j}}$ : If the total energy produced is less than the daily average needs, there is a lack of produced energy. This lack of energy produced can be expressed as follows (Zghal 2011): 


$$
L E G(t)=\left(B_{j}(t)-E_{h}(t)\right) \cdot \eta_{\text {ond }}
$$

$\eta_{\text {ond }}$ : is the inverter efficiency.

- $\mathrm{E}_{\mathrm{h}}=\mathrm{Bj}$ : If the produced total energy equals the consumption, there is neither an excess nor a lack.

- $\mathrm{E}_{\mathrm{h}}>\mathrm{Bj}$ : If the produced energy is larger than the need of the user, so the produced power is in excess.

From the determination of $B_{j}$, we will try to present the optimal characteristics of the different components of the installation. To attain this objective, we are based on the criteria of lack (LEG).

The determination of optimal characteristics will guarantee us the presentation of an optimal autonomous hybrid system.

\section{Case study}

As previously mentioned, a mathematic model for the technical optimization of the autonomous hybrid system (solar-wind) is disposed. As a case of study, this model is applied to analyze a project which is designed to guarantee the energizing demands of a station for pumping water located in Medenine, Tunisia.

\subsection{Presentation of the station:}

The concerned pumping station is situated in the Tunisian southeast in Figure 2, exactly in the North of the governorate of Medenine. The equatorial coordinates of the city of Medenine are characterized by latitude: 33,35 North and longitude: 10 East

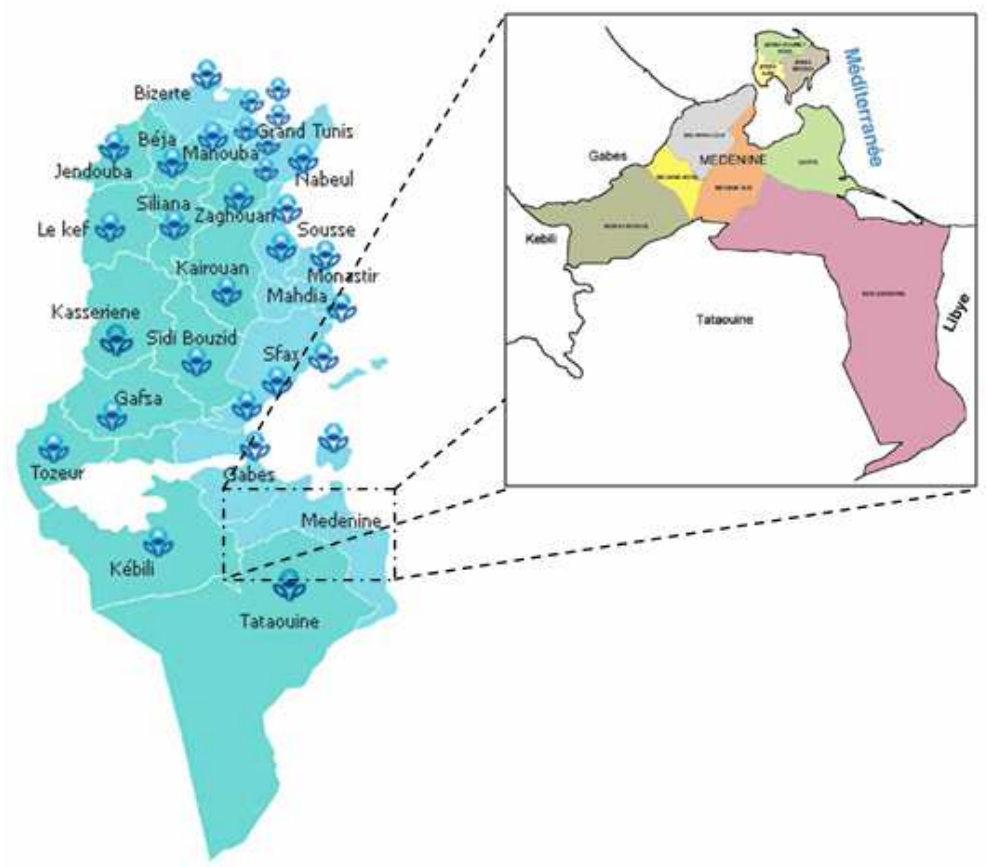

Figure 2. Geographic map of Medenine

Its geographical position (height $116 \mathrm{~m}$ ) and the other weather conditions make the city of Medenine benefits from a dry climate and a remarkable solar potential assured by high values of radiation all over the year. Besides, this region of Southern Tunisia South is also characterized by a pluviometry average between 100 and 150 [mm.year-1], despite, long periods of drought. The governorate of Medenine is characterized by a moderate wind potential, with annual recoverable wind energy of about 269 kWh.m-2.year-1 (Ben Amar 2006).

The existing station is essentially equipped by a photovoltaic generator, a wind turbine and a command system of hybrid energy (photovoltaic and wind energy) to produce electrical power needed to pump water.

- The photovoltaic generator: it is composed of ten single-crystal modules Isofoton (I55), texturized in antireflexive layer. A module is characterized by a nominal power of $55 \mathrm{~W} \pm 10 \%$, a nominal tension of $12 \mathrm{~V}$ and a return supervised between 14 $\%$ and $17 \%$, as "Table1". The photovoltaic panels are installed with a titled angel $35^{\circ}$ near to the latitude of the site $33.35^{\circ}$. 
Table 1. Detailed photovoltaic field configuration

\begin{tabular}{|c|c|}
\hline Panel's characteristics & Isofton I55 \\
\hline Peak power voltage Vn $(\mathbf{V})$ & 12 \\
\hline Peak power Pc $(\mathbf{W c )}$ & $55 \pm 10 \%$ \\
\hline Short circuit current Isc $(\mathbf{A})$ & 3.38 \\
\hline Open circuit voltage $\mathbf{V}_{\text {oc }}(\mathbf{V})$ & 21.6 \\
\hline Current of maximal power Imax $(\mathbf{A})$ & 3.16 \\
\hline Voltage of maximal power Vmax $(\mathbf{V})$ & 17.4 \\
\hline Normal operating cell temperature TONC $\left({ }^{\circ} \mathbf{C}\right)$ & 47 \\
\hline
\end{tabular}

- The wind generator: the wind turbine installed in the station at a level $18 \mathrm{~m}$ is Whisper 200 with 3 pales. Its starting up speed is $3.1 \mathrm{~m} / \mathrm{s}$ and its nominal power is $1 \mathrm{~kW}$ for a speed of $11.6 \mathrm{~m} / \mathrm{s}$, "Table 2 ".

Table 2. Detailed wind generator configuration

\begin{tabular}{|c|c|}
\hline Turbine's characteristics & Whisper 200 \\
\hline Rotor diameter $(\mathbf{m})$ & 2.7 \\
\hline Start up wind sped $(\mathbf{m} / \mathbf{s})$ & 3.1 \\
\hline Rated power $(\mathbf{W})$ & $1000 \mathrm{~W}$ at $11.6 \mathrm{~m} / \mathrm{s}$ \\
\hline kilowatt hours per month $(\mathbf{k W h} / \mathbf{m o n t h})$ & $1580 \mathrm{kWh} / \mathrm{month}$ at $5.4 \mathrm{~m} / \mathrm{s}$ \\
\hline Survival wind speed $(\mathbf{m} / \mathbf{s})$ & 55 \\
\hline Warranty $($ year $)$ & 5 \\
\hline
\end{tabular}

Using the meteorological data of the wind speed and the characteristic curve (Figure 3) that is supplied by the manufacturer which describe the power of wind generator as a function of the wind speed, the electrical energy supplied by the wind turbine for every day during the entire year can be calculated.

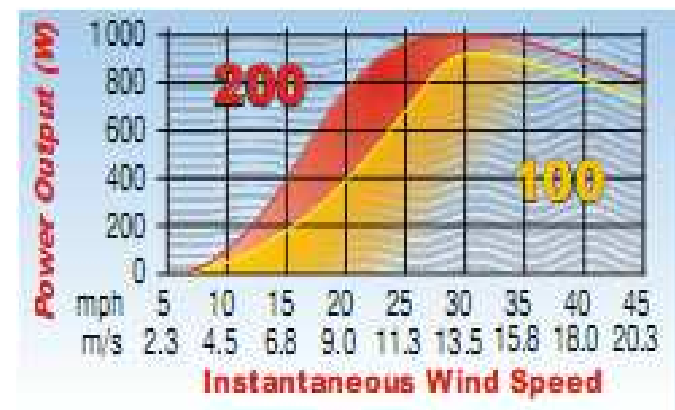

Figure 3. Curve of the output power of the wind turbine Whisper 200 according to the wind speed [catalog Whisper]

The curve of the power at the exit of the wind generator Whisper 200 installed in the present station demonstrates an almost hyperbolic aspect.

- The pump motor: is an electro submerged pump type Grundfos with a nominal power $0.75 \mathrm{CV}=0.55 \mathrm{~kW}$.

- The inverter: is a sinusoidal converter with an input tension of 24V/DC and the output tension is three-phase 220V/AC.

- The reservoir: a pond of water storage featuring a cylindrical shape of $6 \mathrm{~m}$ diameter and $2.5 \mathrm{~m}$ altitude. Its maximal capacity of storage is estimated to $42 \mathrm{~m}^{3}$.

- The well: the characteristics are the following in Figure 4.

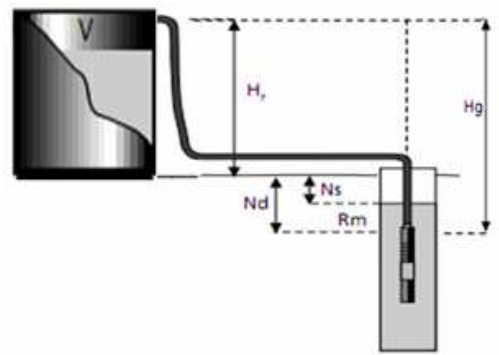

\begin{tabular}{|c|c|}
\hline $\mathrm{Nd}(\mathrm{m})$ & 47 \\
\hline $\mathrm{Ns}(\mathrm{m})$ & 28 \\
\hline $\mathrm{Hr}(\mathrm{m})$ & 2,5 \\
\hline $\mathrm{Hg}(\mathrm{m})$ & 48,5 \\
\hline $\mathrm{HMT}(\mathrm{m})$ & 53.3 \\
\hline
\end{tabular}

Figure 4. Presentation of the station 
The total manometric height (HMT) of a pump is the difference of pressure in meters of column of water between the openings of aspiration and expulsion. This height can be calculated as follows:

$$
\begin{aligned}
& H M T=H_{g}+P_{c} \\
& H_{g}=H_{r}+N_{d}
\end{aligned}
$$

where:

$\mathrm{H}_{\mathrm{g}}$ :geometrical height enters the pumped groundwater ( dynamic level) and the plan of use

$\mathrm{P}_{\mathrm{c}}$ : pressure losses correspond in most to $10 \%$ of the total geometrical height.

$\mathrm{N}_{\mathrm{s}}$ : the static level of a well or a drilling is the distance between the ground and the surface of the water before pumping.

$\mathrm{N}_{\mathrm{d}}$ : the dynamic level is the distance between the ground and the surface of the water for a given debit of pumping.

The difference between the dynamic level and the static level is called dewatering. $\mathrm{R}_{\mathrm{m}}$ is the acceptable maximal dewatering before stopping the pump.

\subsection{Test of the availability of water in the well}

Every well must be tested before being equipped. The test include two step: first one is measuring the maximum debit of pumping water that we can never exceed and the second step is checking whether the well is a renewable source of water or not.

The first test consists on pumping water with different debit and measuring the dynamic level on course of time. The discharge debit of pumping which the dynamic level remains almost constant after a few minutes is considered as the maximal debit of the well. For the studied well, the maximal debit is equal to $3.35 \mathrm{l} / \mathrm{s}$. Moreover, the installed pump should be optimized with the maximum debit of the well.

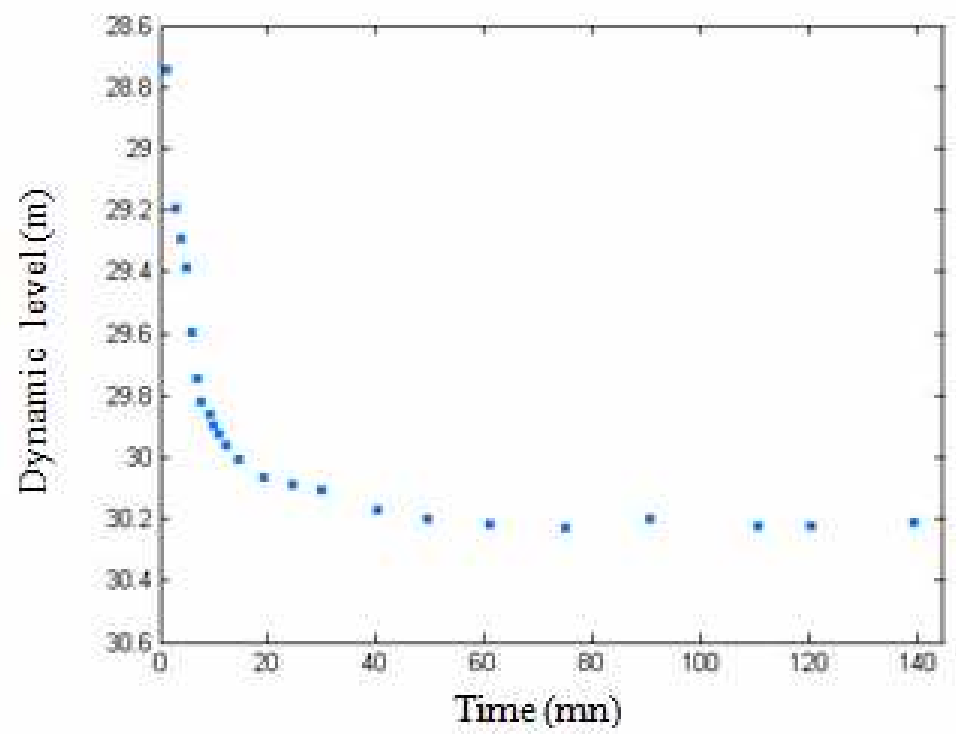

Figure 5. Emptying curve of the well with a debit of $3.351 / \mathrm{s}$

The second test consists on controlling the rise of the dynamic level after stopping pumping water. As shown in Figure 6, the rise goes in a normal way. So, we can deduct that this well is a source of renewable water and we can use it without risks. 


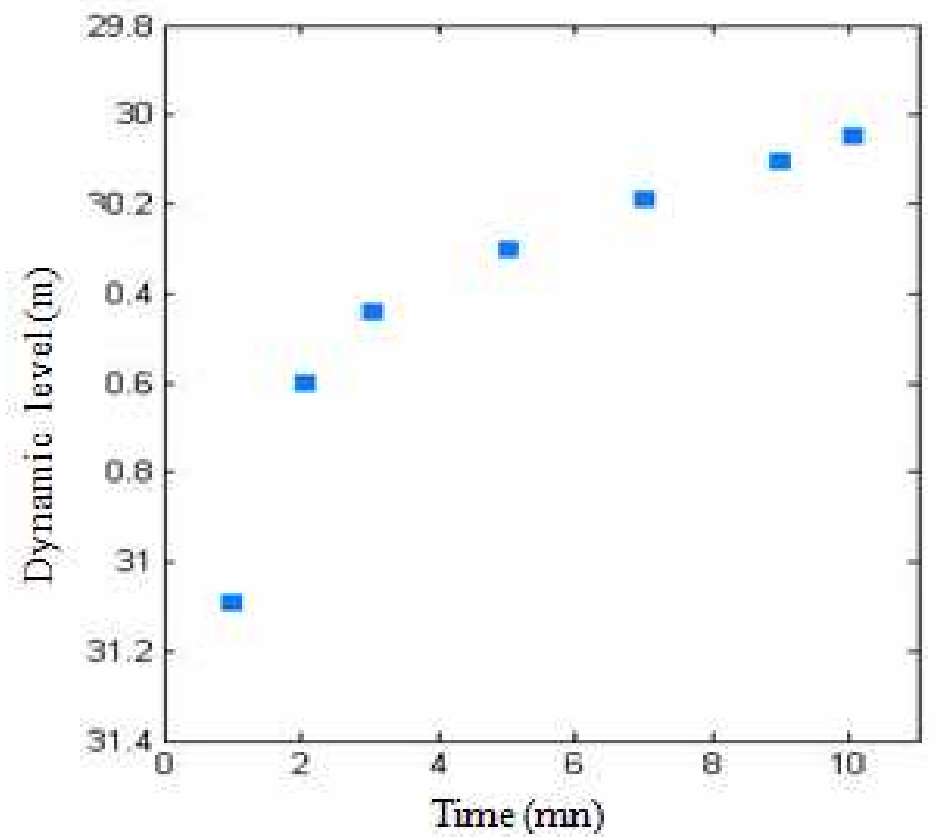

Figure 6. Rise curve of the dynamic level of the well

The studied well is located in a site where there are others wells to irrigate some nearby farms. So, in order to protect them, the Commissionership "CRDA" limits to $0.51 / \mathrm{s}$ by hectare the maximum discharge that we can never exceed. The area to irrigate covers a surface of thectare.

\section{Results and discussion}

As previously mentioned, the objective of our study is to analyze from the technical point of view, an autonomous hybrid (photovoltaic-wind) system. The above mentioned method will be used for this analysis. We have exploited the different mathematical models to implement a Matlab simulation code.

\subsection{Recoverable energies by the photovoltaic system}

The principal objective of this part is the determination of solar energy characteristics et all places and all times. In this context, we will present the different specification of the used solar energy in Medenine, Tunisia as parametric study. Therefore, the comparison is based on the theoretical data calculated for the region of Medenine and the meteorological data measured by the National Institute of the Meteorology of Tunisia in Medenine.

Figure 7 shows the variation of theoretical and measured duration of sunshine in Medenine. The curve of the real duration of sunshine presents very important fluctuations from one day to another in comparison with the curve of the theoretical duration of sunshine length which presents a parabolic profile. The period of the real duration of sunshine varies between 0 and $12.5 \mathrm{~h}$. Indeed, the length of the theoretical duration of sunshine varies between $9.78 \mathrm{~h}$ and $14.21 \mathrm{~h}$.

In order to optimize the hybrid unit for the production of the needed electrical energy for water pumping, a comparison between the theoretical and measured performance of the station is sought. Indeed, the comparison concerns the production of the annual electrical energy susceptible to be collected with the values of the energy really collected. At present, and since the breakdown of the wind turbine in January, 2009 after the destruction of one blade, only a comparison of the photovoltaic production only is achieved. The measures presented in this study which extend over a period of time of one year show the daily variation of the electrical energy produced by the existing solar panels.

Figure 8 presents the measured and the theoretical daily production of the electrical energy supplied by the photovoltaic generator during one year. One notice that the curve of the measured electric energy presents a fluctuating speed at the rate of days, which presents a profile similar to the theoretical curve yet a lower level, is remarkable. The daily fluctuations in the electric energy production are mainly due to the lack of precise protocols that register the standing order of the data. Also notice that the measured values of the maximal intensity of the daily electric production is always below the theoretical values. 


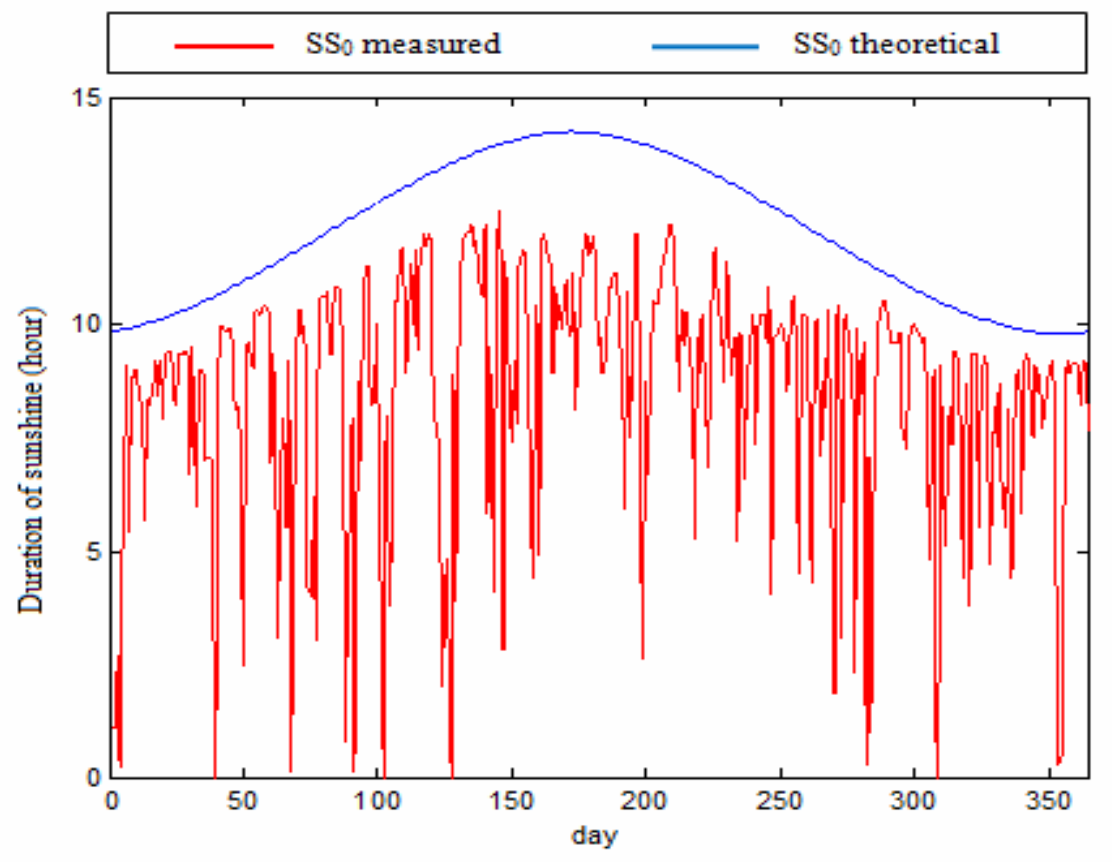

Figure 7. Variation of the daily duration of sunshine in Medenine for one year

The gap between measured and simulated profile is explained by many factors, the most important is the fact to apply a model based on the hypothesis of a clear sky in all days along the year with a maximal radiation calculated at midday $12 \mathrm{~h}$ which is extended for all the day. However, the profile of radiation is extremely variable along one day. Moreover, the real energy received (theoretical and measured) by the fields is proportional to the duration of sunshine (theoretical and measured) and as it is shown in Figure 7, there is a gap between the profile of the measured duration of sunshine and the calculated one.

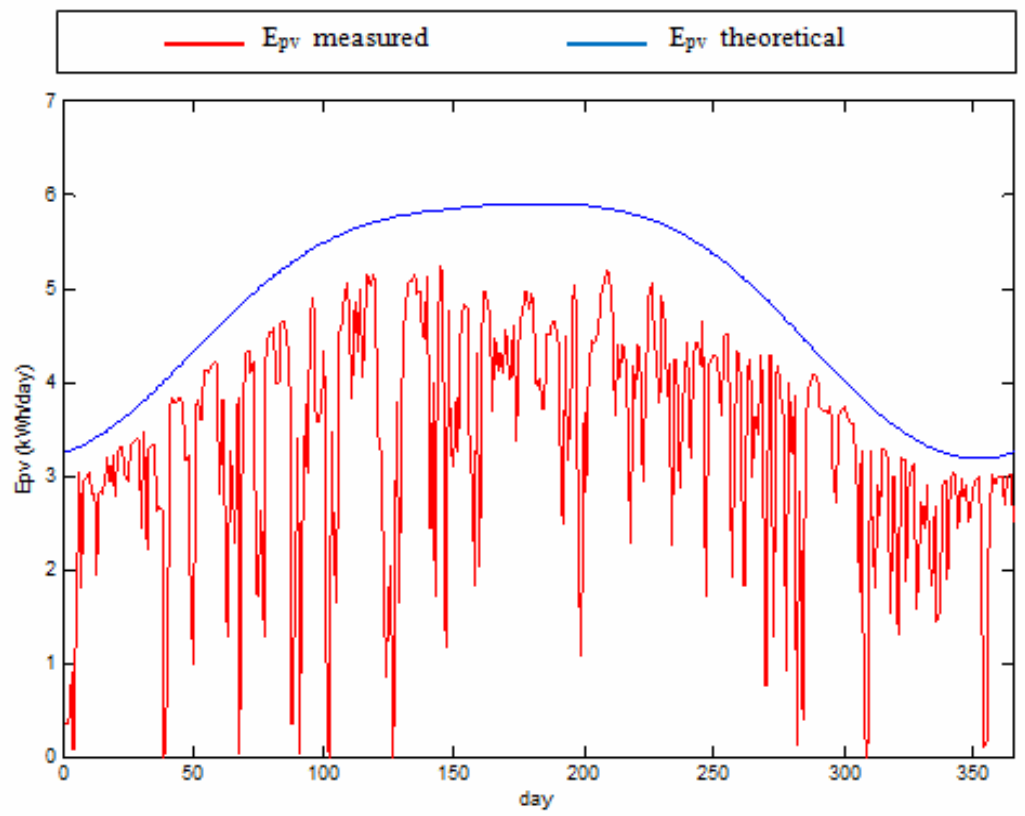

Figure 8. Comparison between the measured and the theoretical daily variation of the electrical energy supplied by the photovoltaic generator during one year

\subsection{Recoverable energies by the wind generator}

Based on the wind speed given by the meteorological data, we notice that the curve presents a very fluctuating behavior along the year. The wind speed can reach peaks of $9 \mathrm{~m} / \mathrm{s}$, however as there are little windy days the average speed reduces to $3 \mathrm{~m} / \mathrm{s}$. Figure 9 
presents the daily wind speed measured in a sea level of $18 \mathrm{~m}$. To calculate the wind speed at the height of $18 \mathrm{~m}$, we have used formula (19).

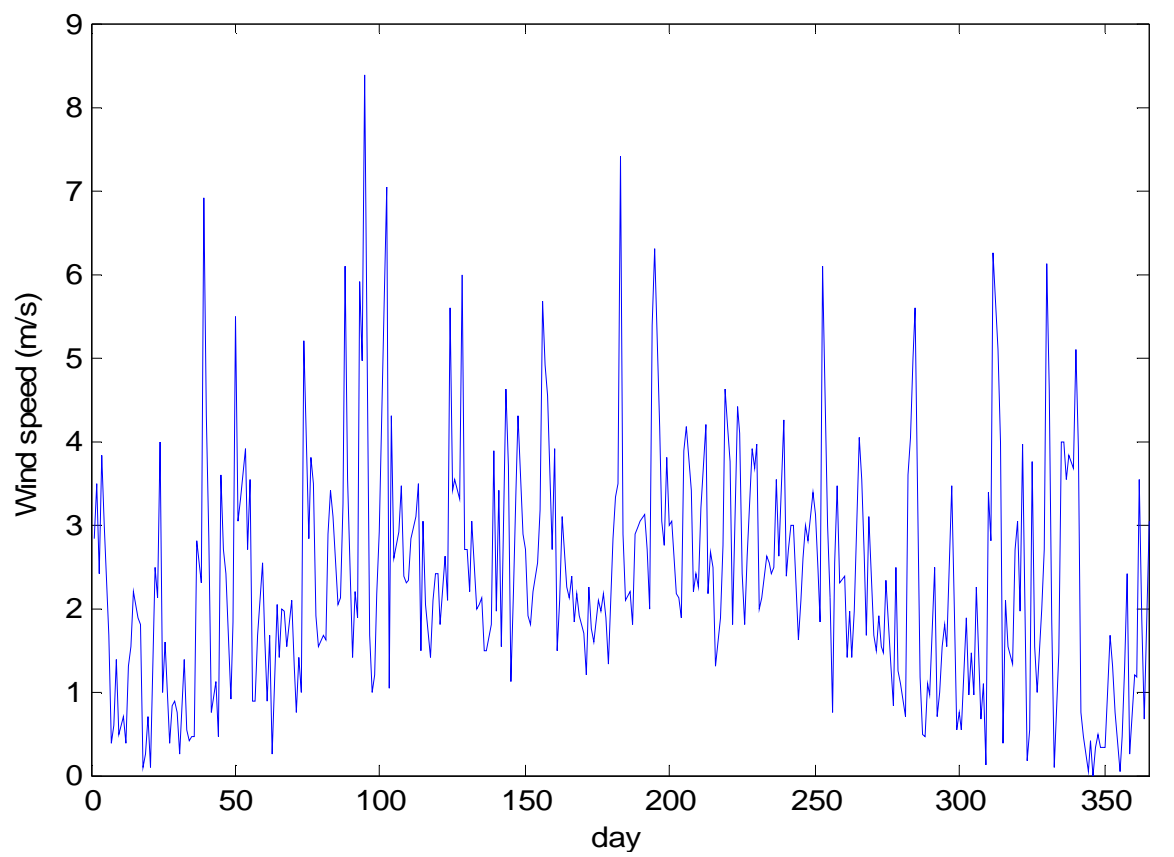

Figure 9. Daily variation of the wind speed in Medenine for year 2002 at a height of $18 \mathrm{~m}$

Based on the meteorological data of wind speed and the characteristic curve of the power at the exit of wind generator Whisper 200 installed in the station which is given by the Fig 2 of the appendix according to the wind speed, we were able to calculate the electrical energy supplied by the wind turbine for every day during one year, the result is presented in Figure 10.

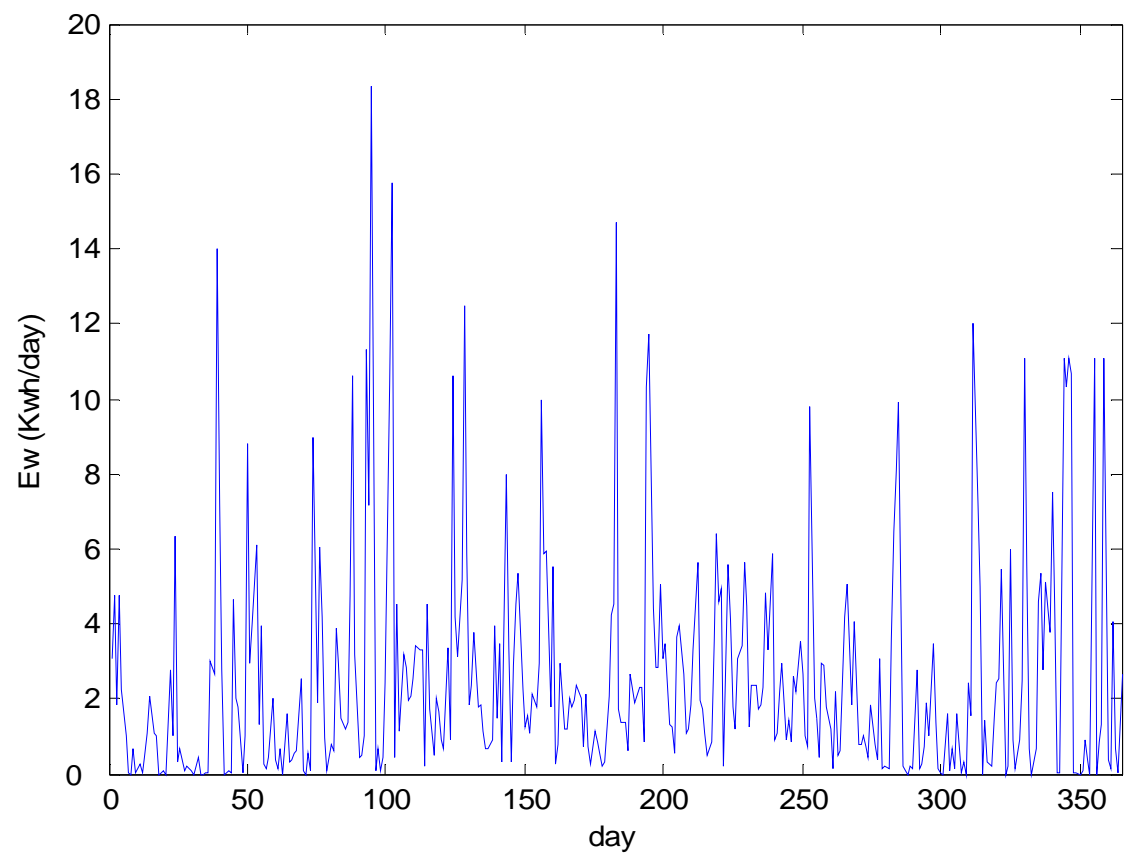

Figure 10. Daily variation of the electrical energy recovered by the wind generator during one year

\subsection{Recoverable energies by the hybrid system}

The objective of this part is the determination of recoverable energy by the hybrid system. In this context, the energy recovered by the wind generator is added to the measured energy recovered by the photovoltaic field, Figure 11. 


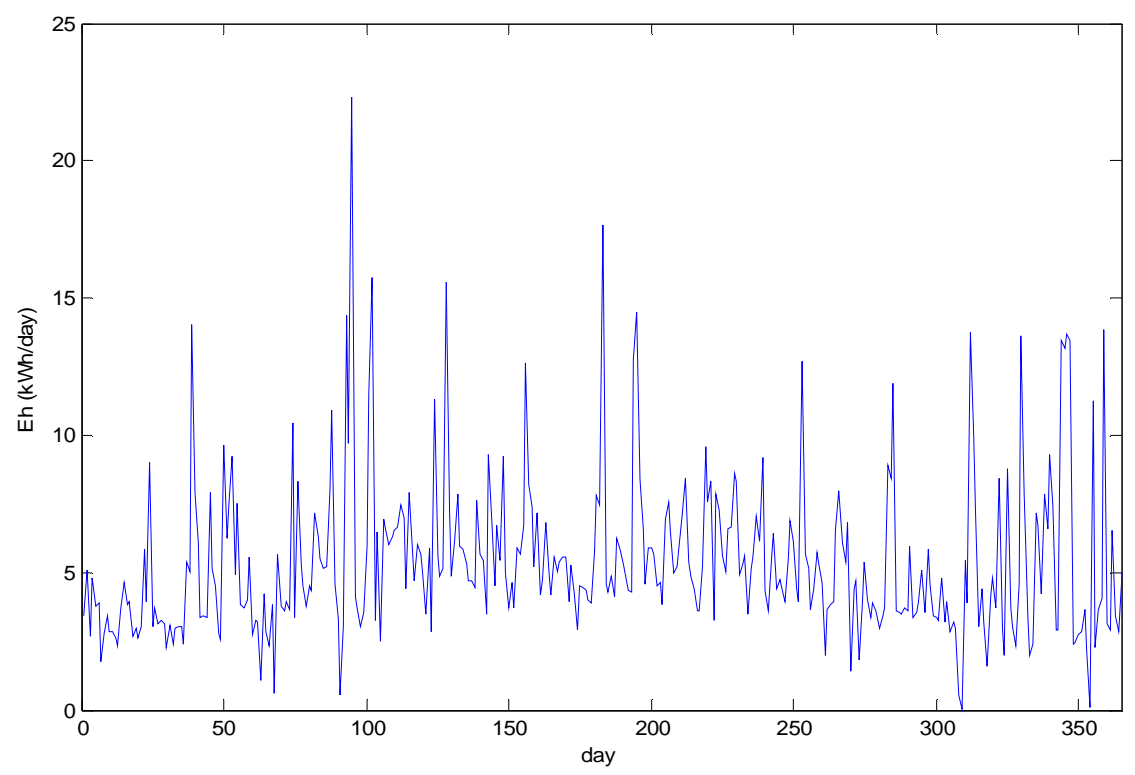

Figure 11. Daily variation of the recovered energy by the hybrid system for $\beta=35^{\circ}$

The daily variation of the recovered hybrid energy present an important fluctuation which due to the fluctuations presented on the curves of the measured energy recovered by the panels for incline angle equal to $35^{\circ}$ and the wind energy. In a first level, we look for optimizing the existing system by reducing the lack of energy. We studied the influence of the pumping water duration on the number of lack's days and the lack of energy to generate probability (LEG) for different pumping duration ( $2 \mathrm{~h}, 3 \mathrm{~h}, 4 \mathrm{~h}, 5 \mathrm{~h}, 6 \mathrm{~h}$, 7h), Figure 12.

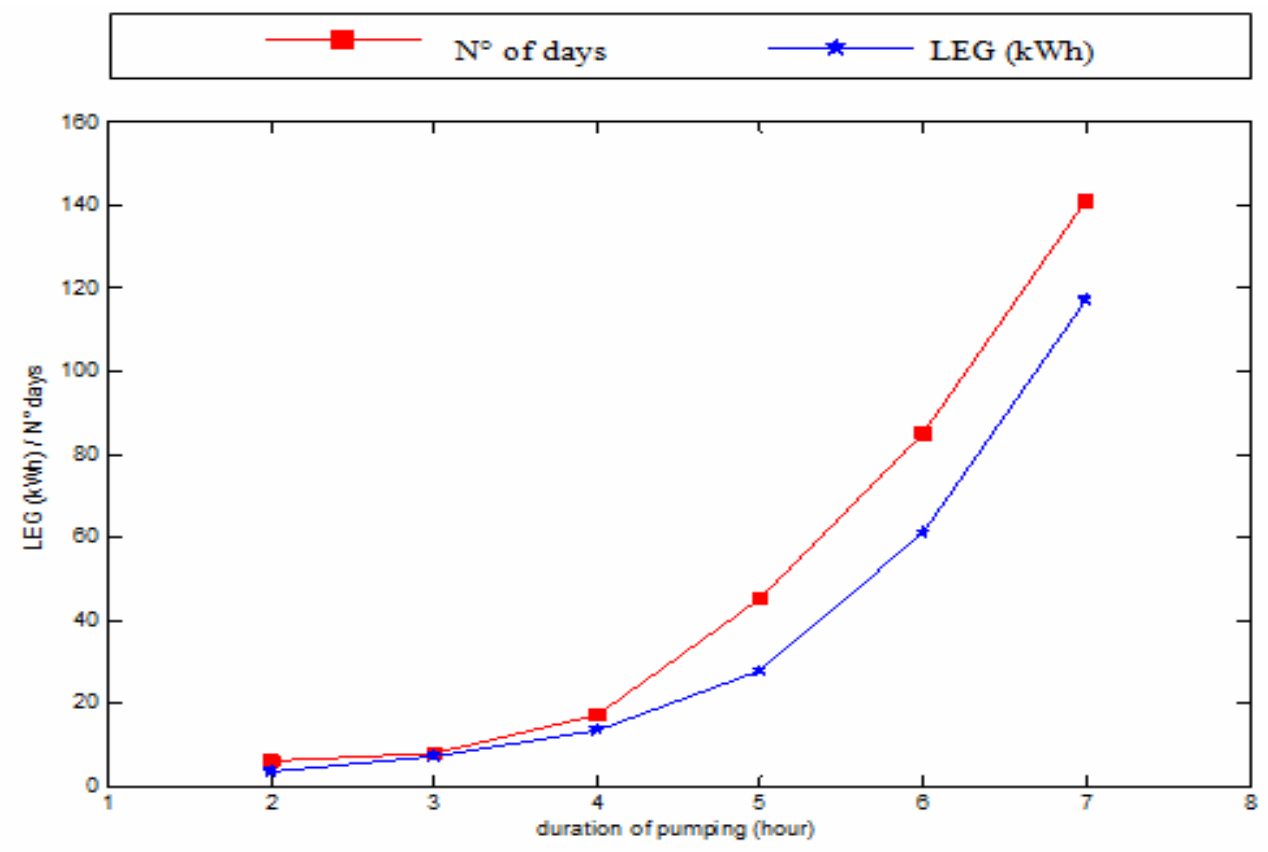

Figure 12. Influence of the duration of pumping on the lack of energy (LEG) and the number of the days of lack

We notice that the change of the pumping duration influence on the daily average needs $\left(\mathrm{B}_{\mathrm{j}}\right)$ and the lack of energy (LEG).

Figure 12 shows that the increasing of pumping water duration increases the daily need of energy as a result the lack of energy and the number of lack's days become more important. Indeed, the duration $\mathrm{D}=2 \mathrm{~h}$ is the optimal pumping duration of this station with a yearly lack equal to $3.62 \mathrm{kWh}$ and there is a few days (6 days) when the of electric energy need is not satisfied, Figure 13. 


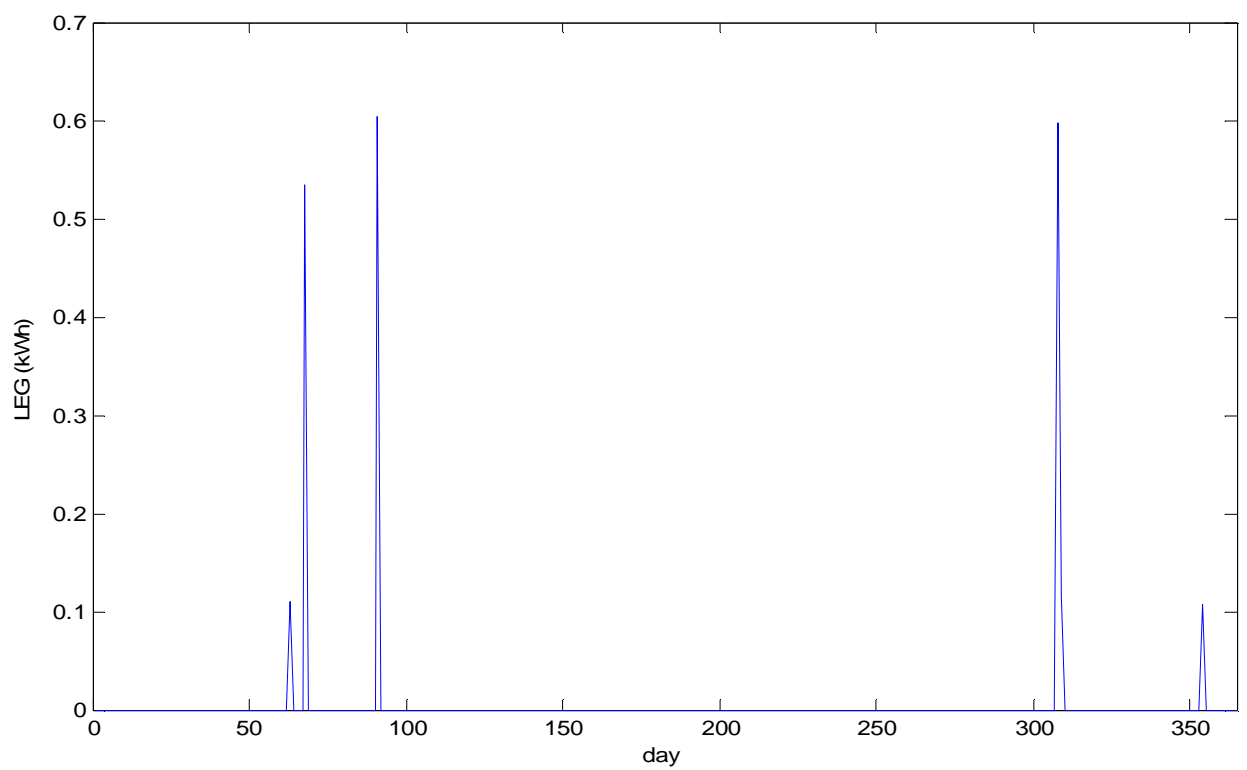

Figure 13. Lack of energy (LEG) for a pumping duration $D=2 h$.

Figure 13 present the lack of energy of the hybrid system for a pumping duration $D=2 \mathrm{~h}$. There is six days when the energy produced is less than the needs energy. Among these days, there is two days successive $\left(308^{\text {th }}\right.$ and $\left.309^{\text {th }}\right)$ and the others are not successive. According this result, there is no pain of lack on water because of the reservoir volume $42 \mathrm{~m}^{3}(\approx 12$ times the daily need on water). The duration $2 \mathrm{~h}$ is insufficient to satisfy the needs for irrigation of the cultivated surface, therefore we assume to fix the pumping duration to $5 \mathrm{~h}$ and to determine the optimal incline angle of the photovoltaic panels.

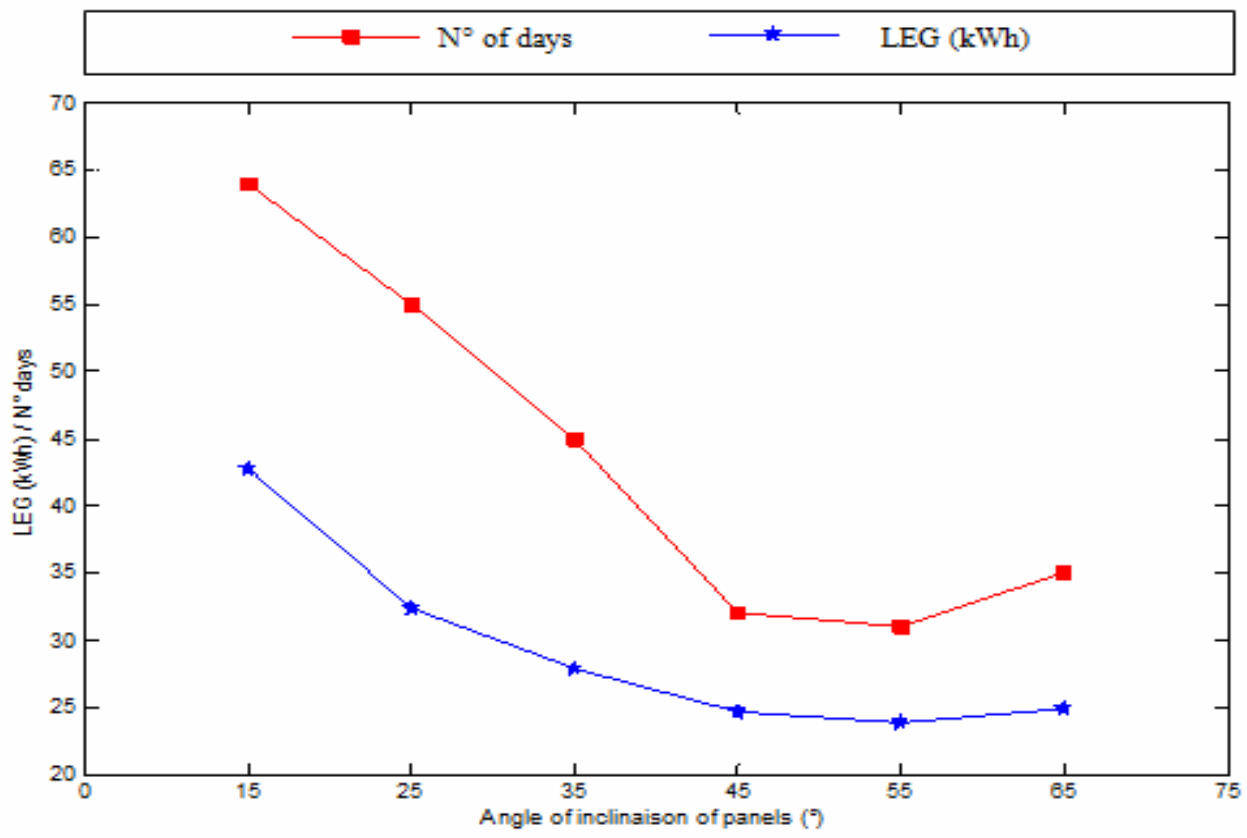

Figure 14. Influence of the inclination angle on the number of the days of energy lack

In the previous research works (Perrin 1963; Schwartz 1980; Zghal 2012), the authors express that the optimal incline angle equals to the site latitude. During the winter months, insufficient energy is supplied hence an angle which minimizes the lack of energy in this period of the year is chosen. When the angle increases, the energy is more important in winter months however it decreases in summer months. In the same way, small values of the incline angle are of favor in summer months. We notice that the change of the incline angle is followed by a variation of the recovered solar energy. Similar observation for the number of the days when there is lack of energy. As effect, Figure 14 provide a minimum value of tilt angle $55^{\circ}$ for a duration pumping $\mathrm{D}=5 \mathrm{~h}$. So, the angle $55^{\circ}$ is considered as the optimal angle of inclination which is suitable for the site with only 31 days of lack and LEG 
equal to $23.83 \mathrm{kWh}$ for a pumping duration. On the other hand (angle equal to $35^{\circ}$ ), the day number of lack is 45 with an energy lack equal to $27.84 \mathrm{kWh}$. The values of total energy for an angle of $55^{\circ}$ is more important than the values of the total energy for an angle of $35^{\circ}$ in the winter and autumn months and inversely for the summer and spring period.

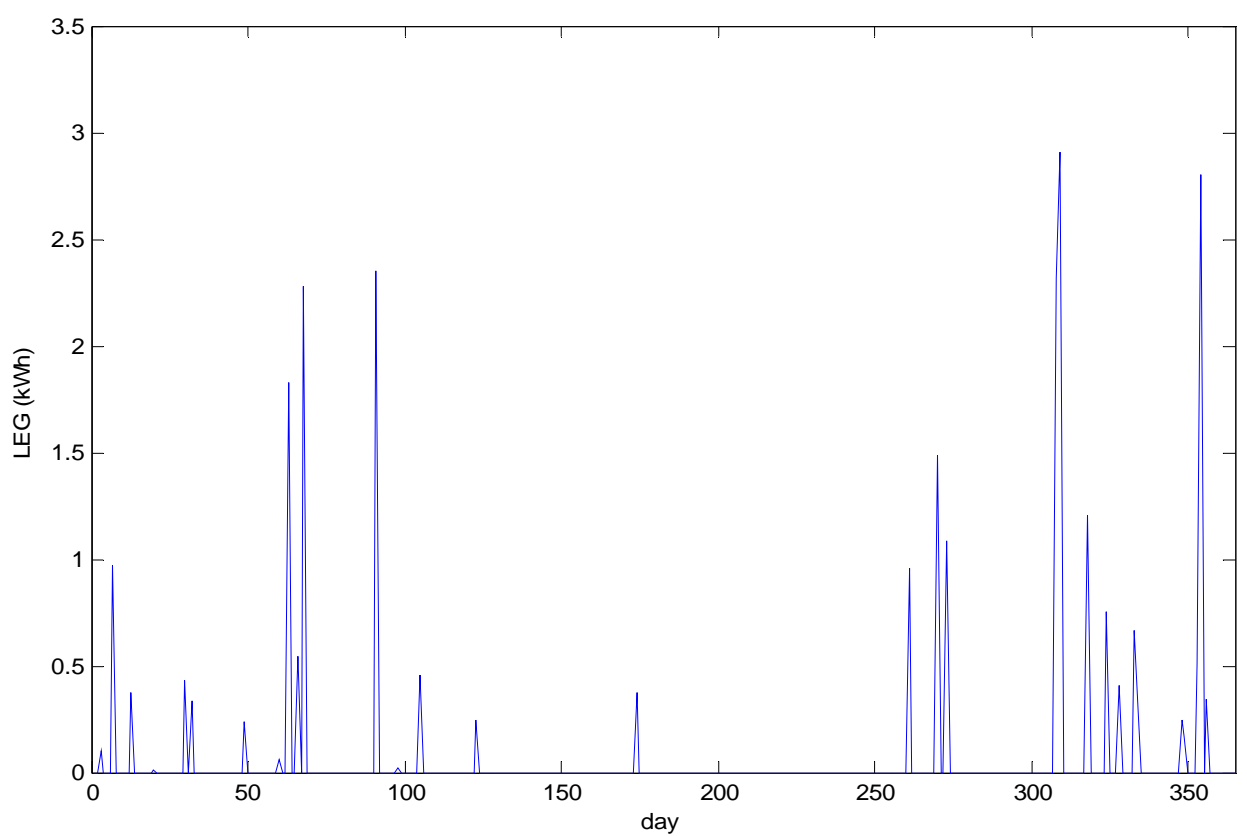

Figure 15. Lack of energy (LEG) for a pumping duration $D=5 \mathrm{~h}$.

In this setting, Figure 14 shows a presentation of the lack energy for the optimal incline angle $55^{\circ}$. The number of days lack is 31 Figure 15 present the lack of energy of the hybrid system for a pumping duration $\mathrm{D}=5 \mathrm{~h}$. There is 31 days when the energy produced is less than the needs energy. Among these days, the maximum of successive days of lack energy is two days there. Therefore, we don't have a risk of lack on water because of the reservoir volume $42 \mathrm{~m}^{3}(\approx 5$ times the daily need on water).

\section{Conclusion}

The study is realized in association with the regional commissionership of agricultural development of Medenine (CRDA) for the use of the renewable energy for the decentralized production of electricity. To apply our theoretical approach constituted on the technical optimization of an autonomous hybrid energy system for pumping water located in the Southern Tunisia by developing an algorithm allowing the determination of the optimal properties of the installation that answer the requirements of the user. In this study, the following procedure is used:

- test the availability of water of the well,

- estimation of the energy needs of the consumer,

- estimation of the electrical energy produced by the photovoltaic system,

- estimation of the electrical energy produced by the wind system,

- estimation of the electrical energy produced by the hybrid system ( wind solar energy),

- technical optimization of the hybrid unit for pumping water.

The technical analysis of the energy needs of the station and the quantity of energy using various solar or wind sensors requires the determination of the lack of energy produced LEG. Determining the variation of this parameter as function of the pumping water duration and the incline angle of the panels allows to verify the autonomy of the pumping plant and to adjust the characteristics of the various elements of the conversion system. Finally, we notice that the optimization of a hybrid unit for pumping water existing in an isolated site, is worthy of being studied because of its economic and environmental benefits. The results of the simulation show that the solar energy is an ideal solution in Medenine and introducing a wind generator into an autonomous photovoltaic system to reduce the period of lack of electrical energy, is interesting.

\section{Nomenclature}

$a \quad$ Coefficient which varies from 0,1 to 0,4

$B \quad$ Temperature coefficient

$B_{j} \quad$ Daily energy needs (kWh/day)

$\mathrm{CC}$ Correction of the equation of time 


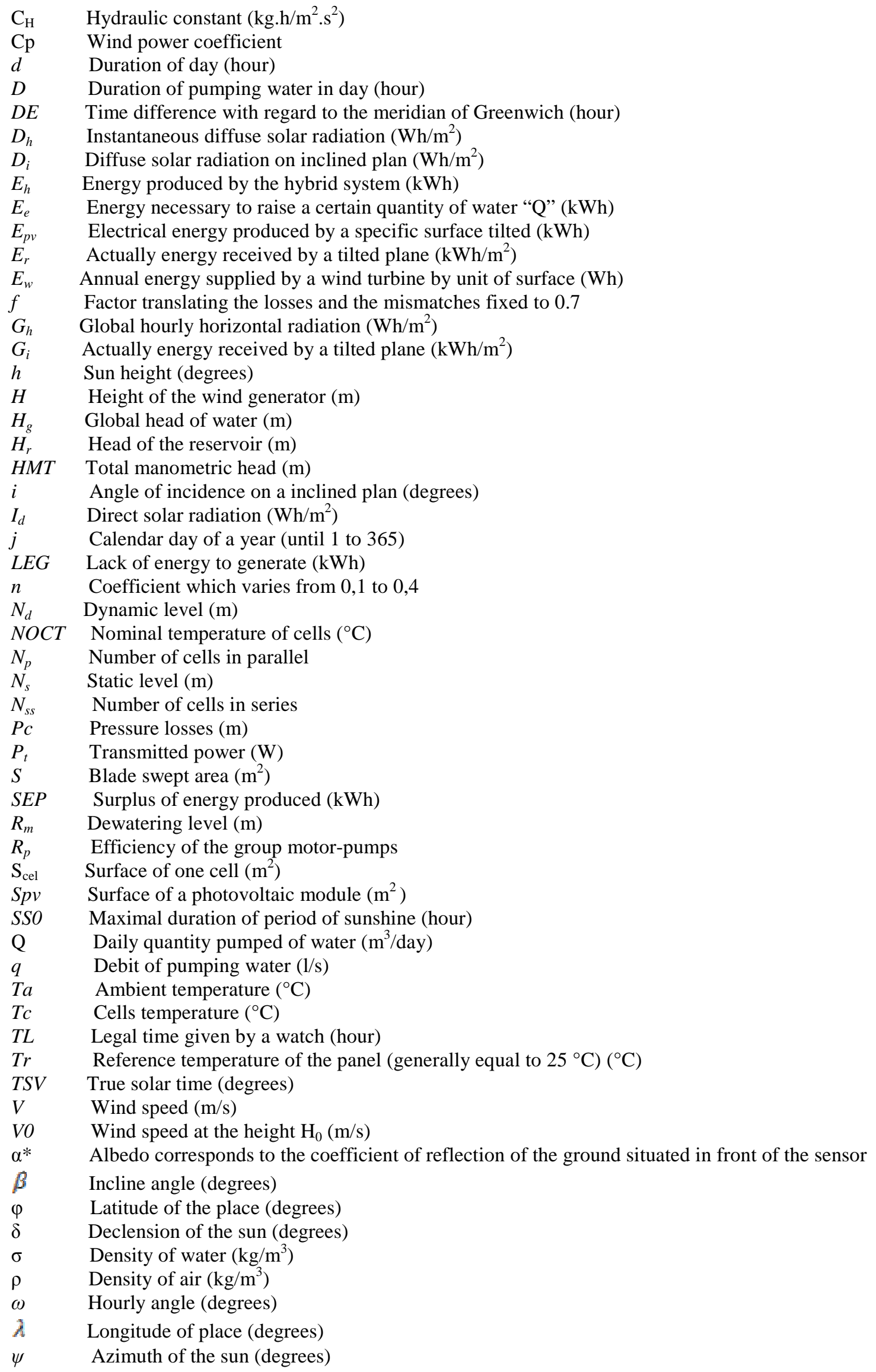




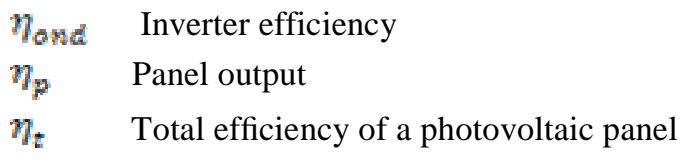

\section{Acknowledgement}

This study was conducted in the framework of charity travel in association with the Regional Commission for Agricultural Development in Medenine (CRDA) to provide the farm work in the Association of the handicapped persons in Medenine.

\section{References}

CH. Perrin DE BRICHAMBAUT, 1963. Rayonnement solaire et échanges radiatifs naturels. Gauthier Villars.

Djavad Fauladgar, 1980. Contribution to the analysis and the temporal modeling of the direct solar radiance. Academic doctorate thesis, University Paul Sabatier of Toulouse.

Fathi ben Amar, 2006. Potentiel énergétique éolien en Tunisie. International Congress on the Engineering of Renewable Energies, CERE 2006-Hammamet, Tunisia.

H. Yang, L. Lu, W Zhou, 2007. A novel optimization sizing model for hybrid solar-wind power generation system. Solar Energy, $81,76-84$.

Hrayshat, Mohammed S. Al-Soud, 2004. Potential of solar energy development for water pumping in Jordan. Renewable energy , 29, 1393-1399.

Kolhe M, Agbossou K, Hamelin J, Bose TK., 2003. Analytical model for predicting the performance of photovoltaic array coupled with a wind turbine in a standalone renewable energy system based on hydrogen. Renew Energy, 28, 727-742.

L.M Schwartz, R. Louat et G. Menguy, 1980. Etude du rayonnement solaire global à Lyon et à Mâcon. Revue Phys, 15, 103-112.

Najoua ZARAI, Maher CHAABANE, Slimane GABSI, 2010. Outil de planification de la production thermique des capteurs solaires. International Renewable Energy Congress November 5-7, 2010- Sousse, Tunisia.

Nandi Sanjoy Kumar, Ghosh Himangshu Ranjan, 2010. Prospect of wind-PV-battery hybrid power system as an alternative to grid extension in Bangladesh. Energy, 35, 3040-7.

R. Yaiche, 2007. Logiciel de calcul des paramètres astronomiques. Revue Energies Renouvelables ICRESD-07 Tlemcen, 343 348.

R.F.Mechlouch er A.Ben Brahim, 2003. Choix d'un modèle d'ensoleillement et détermination des inclinaisons optimales des capteurs héliothermiques pour la ville de Gabes en Tunisie. Revenue des énergies renouvelables, 6 (1).

Romdhane Ben Slama, 2010. Incidental solar radiation on the various vertical walls of a building following time variations. Séminaire International sur le Génie Climatique et l'Energétique (SIGCLE 2010).

W. Zghal , G. Kantchev, H. Kchaou, 2011. Determination of recoverable wind energy for electricity generation using wind energy conversion system in Tunisia. International Journal of Engineering, Science and Technology, 3 (5), 83-92.

Zghal Wissem, Kantchev Gueorgui, Kchaou Hédi, 2012. Modeling and technical economic optimization of an autonomous photovoltaic system. Energy, 37, 263-272.

Zghal Wissem, Kantchev Gueorgui, Kchaou Hédi, 2011. Optimization and management of the energy produced by a wind energizing system. Renewable and Sustainable Energy Reviews, 15, 1080-8.

\section{Biographical notes}

S. Laamari pursues these doctoral studies in Mechanical Genius. He received his master degree from the National Engineering School of Sfax Tunisia in Mechanical and Engineering option new and renewable energies in 2009 and engineering degree in Electromechanical from the National Engineering School of Sfax Tunisia in 2008. His area of interest is Renewable Energy and essentially the solar energy and the solar desalination. Ms. Laamari is currently a researcher in the Laboratory of Electromechanical Systems in the National Engineering School of Sfax, Tunisia.

Dr. W. Zghal received a PhD in Mechanical Genius from the National Engineering School of Sfax, Tunisia in 2012. He received his master degree from the National Engineering School of Sfax Tunisia in Mechanical and Engineering option new and renewable energies and engineering degree in Electromechanical from the National Engineering School of Sfax Tunisia in the year 2008 and 2007 respectively. His area of interest is Renewable Energy and essentially the wind energy and the solar energy. He has published 3 research papers in different international journals and conferences. Mr. Zghal is currently a researcher in the Laboratory of Electromechanical Systems in the National Engineering School of Sfax, Tunisia.

Dr. H. Kchaou received his Master degree in Mechanical engineering from the National Engineering School of Tunis in1988 and a PhD in Applied Mechanics from the National Engineering School of Sfax in 1996, Tunisia. He is interested in the field of numerical analysis of mechanical problem, Computational Fluid Dynamics "CFD" and renewable energy. He is author of different articles published in different international journals and conferences. Currently, Mr. Kchaou is Associate Professor of Mechanical engineering at Preparatory School Institute of Engineering Studies of Sfax, Tunisia. He is also member in the Laboratory of Electromechanical Systems in the National Engineering School of Sfax, Tunisia.

Received November 2014

Accepted March 2015

Final acceptance in revised form March 2015 